\title{
CORRECTION
}

View Article Online

View Journal / View Issue

\section{D) Check for updates Correction: Hydrogel networks as underwater contact adhesives for different surfaces}

Cite this: Mater. Horiz., 2020,

7, 2168

\author{
Pan Feng, $\dagger^{\text {abc }}$ Shaoxiong Ye, $\dagger^{\mathrm{a}}$ Ruixing Wang, ${ }^{\mathrm{a}}$ Wei She, ${ }^{\text {ac }}$ Jiaping Liu, ${ }^{\text {ac }}$ \\ ZhengMing Sun ${ }^{\star b}$ and Wei Zhang ${ }^{\star b}$
}

DOI: $10.1039 / \mathrm{d} 0 \mathrm{mh} 90050 \mathrm{~h}$

Correction for 'Hydrogel networks as underwater contact adhesives for different surfaces' by Pan Feng et al., Mater. Horiz., 2020, DOI: 10.1039/d0mh00176g.

rsc.li/materials-horizons

The authors regret that the name of the first author was incorrectly given as Feng Pan in the originally published manuscript. The correct name of the first author is Pan Feng and the corrected list of authors for this paper is as shown above.

The Royal Society of Chemistry apologises for these errors and any consequent inconvenience to authors and readers.

\footnotetext{
${ }^{a}$ Jiangsu Key Laboratory of Construction Materials, School of Materials Science and Engineering, Southeast University, Nanjing, Jiangsu 211189, China. E-mail: ljp@seu.edu.cn,zmsun@seu.edu.cn,w69zhang@seu.edu.cn

${ }^{b}$ Jiangsu Key Laboratory of Advanced Metallic Materials, School of Materials Science and Engineering, Southeast University, Nanjing, Jiangsu 211189, China

${ }^{c}$ State Key Laboratory of High Performance Civil Engineering Materials, Nanjing, Jiangsu 210008, China

$\dagger$ These authors contributed equally to this work.
} 